Brit. J. industr. Med., 1965, 22, 38.

\title{
RESPIRATORY SYMPTOMS IN MEN WHO HAD PREVIOUSLY WORKED IN A FLAX MILL IN NORTHERN IRELAND
}

\author{
BY \\ P. C. ELWOOD* \\ From the Department of Social and Preventive Medicine, The Queen's University of Belfast
}

(RECEIVED FOR PUBLICATION JULY 6, 1964)

\begin{abstract}
An attempt was made to assess the importance of selective discharge by death or retirement of workers with respiratory symptoms in a flax mill in Northern Ireland.

One hundred and two men who had worked in a flax mill during 1952-62 and who were aged 35 years or more at the time of leaving were followed up. Fourteen of the men had died and 75 were interviewed. The proportion who had dyspnoea on exertion at the time of interview was significantly higher (at $\mathbf{P}<0.05$ ) in those who had had byssinosis than in those who had not had byssinosis while in the mill, although the proportions with dyspnoea in preparers and nonpreparers did not differ significantly. The proportion who stated that they had left the mill because of exertional dyspnoea of increasing severity was also significantly higher among those who had had byssinosis than among those who had not. Most of the men who had had byssinosis stated that their symptoms had improved after they left the mill, though some thought that work in the mill had permanently affected their chests, and two said that their symptoms had become gradually more severe since discharge. Of the 14 who had died, certificates of the cause of death were traced for 12, in none of which had respiratory disease been entered as a cause of death. In one man who had been a flax preparer, chronic bronchitis had been considered a 'significant condition, contributing to the death'.

The study indicates that any estimate of the prevalence of byssinosis based solely on the examination of workers in the mills underestimates the true magnitude of the problem.
\end{abstract}

The assessment of an industrial hazard based solely on a study of those working in the industry is open to certain objections. Selection of workers entering the industry may occur, and those who leave before the normal age of retirement may do so because they find themselves unfit, or are rendered so, by the work they perform, or their death may be caused or contributed to by their occupation. Such selective recruitment and discharge from the industry may lead to an underestimation of the importance of the hazard under study.

Purdon $(1873,1875,1877)$ appears to have been the first writer to stress and attempt to assess these sources of error in the flax industry. He examined all death registrations in six dispensary districts of Belfast in 1872 and found that death rates from

*Now at the Medical Research Council's Epidemiological Research Unit (South Wales). 'phthisis and chest affections' were 'exceedingly high', 31 per 1,000 in preparing room workers compared with 11 per 1,000 in sorters and roughers, five per 1,000 in winders, and one per 1,000 in reelers (Purdon, 1873). In a later examination of the ages and duration of occupation of workers in 50 flax mills in and around Belfast (Purdon, 1875), he commented on the shortness of the working life of operatives in the card rooms, preparing rooms, and dressing departments in the flax industry. He also noticed that the death rates from respiratory disease among 'machine boys' in the industry were relatively low but pointed out that '. . . when the workers begin to feel the effects of the dust ... they seek to obtain employment in other departments which are more healthy' and 'on account of the change of occupation their deaths have to be placed in another class' (Purdon, 1877). 
Errors of this kind have been shown to occur in other industries (Heasman, Liddell, and Reid, 1958; General Register Office, 1958; Cochrane and Higgins, 1961). The size of these errors will vary within any industry from time to time and in different areas since the availability of alternative employment and other social factors may influence whether or not a worker, whose health has been affected by his work, will leave that industry.

In order to examine these factors and attempt to assess their importance in the flax industry in Northern Ireland it was decided to follow up a group of workers who had left a flax mill. It was hoped to ascertain the general medical condition of each at the time of interview, and to discover why those who had worked in preparing departments and those who had been affected by byssinosis had left the mill, and in particular if they had had to leave or had died because of chest trouble. It was also hoped to throw further light on the natural history of byssinosis.

\section{Method}

The study was based on a large country mill in which only flax was processed and in which almost 500 men and 500 women were usually employed. An attempt was made to see all male workers who had left between January 1952 and July 1962 and who had been aged 35 years or more at the time of leaving. Mill records were used to locate discharged workers.

The men were seen in their homes and asked questions about current respiratory symptoms and about smoking habit at the time of interview. Each was then asked questions about respiratory symptoms related to the day of the week and hour of the day before retirement from the mill. Each was also asked about reasons for having left the mill, his general medical condition at the time of discharge and since discharge, and his own belief as to whether or not any permanent effect on his health had been caused by work in the mill. At the end of each interview details relating to occupation in the mill were obtained.

In this report, occupations in the mills have been grouped into 'preparing' (all occupations up to but not including wet spinning) and 'non-preparing' (all other occupations together).

Symptoms of chronic bronchitis were graded at three levels based on the grading of phlegm and previous chest illness as suggested in the Instructions for the Use of the Questionnaire on Respiratory Symptoms (Medical Research Council, 1960):

Grade $\mathrm{O}$, no chronic bronchitis. No evidence of the production of phlegm from the chest of sufficient severity to be graded below.

Grade S, simple chronic bronchitis. Evidence of the production of phlegm from the chest first thing in the morning and/or during the day and/or night, on most days for a period of at least three months each year, for at least the past two years without a recent exacerbation as described below.
Grade E, chronic bronchitis with an exacerbation. Evidence of the presence of simple chronic bronchitis as defined above, but including a period of increased production of phlegm lasting three weeks or more within the last three years, and/or a chest illness with an increased production of phlegm causing an absence from work for at least one week within the last three years.

Exertional dyspnoea was graded as suggested in the same instructions (Medical Research Council, 1960) as follows:

Grade I: No evidence of dyspnoea when hurrying on the level or walking up a slight incline.

Grade II: Evidence of dyspnoea when hurrying on the level and/or walking up a slight incline but not when walking at an ordinary speed on the level.

Grade III: Evidence of dyspnoea when walking at an ordinary speed on the level but not sufficient to necessitate stopping for breath.

Grade IV: Evidence of dyspnoea of sufficient severity when walking at an ordinary speed on the level to necessitate stopping for breath.

Workers who answered 'yes' to the question 'Have you ever had heart trouble?' together with those who were seen to be physically disabled from walking were omitted from all analyses of this symptom.

Symptoms of byssinosis were graded at four levels which closely follow those used by Roach and Schilling (1960), as follows:

Grade 0: No evidence of breathlessness or chest tightness, or discomfort of the chest on Mondays, nor of cough or wheezing which is worse on Mondays than on other days.

Grade $\frac{1}{2}$ : Evidence of breathlessness and/or chest tightness and/or discomfort of the chest on some Mondays, and/or cough or wheezing which is always worse on Mondays than on other days.

Grade I: Evidence of breathlessness and/or chest tightness on every Monday but not on other days.

Grade II: Evidence of breathlessness and/or chest tightness and/or discomfort of the chest on every Monday and also on some other days, provided that at one time in the past symptoms were confined to Monday.

'Monday' is used to imply the working hours, or the period immediately following (i.e., the period spent travelling home from work), during the first day of each working week.

\section{Results}

Of the 102 workers who had left the mill, 14 had died since discharge, two were in hospital, eight had left the country, and three could not be traced. Seventy-five men were therefore interviewed. The distribution of the total group according to the occupation while in the mill is shown in Table 1 , and the following discussion relates to the 75 men interviewed. The 14 men who had died are discussed later.

All the men interviewed had worked for at least 10 years in the mill, 42 mainly in preparing, 33 mainly in non-preparing rooms. Twenty-three of 
TABLE 1

DISTRIBUTION OF WORKERS BY OCCUPATION

\begin{tabular}{l|c|c|c}
\hline \multicolumn{1}{c|}{ No. of Workers } & Preparers & Non-preparers & Totals \\
\cline { 2 - 4 } Interviewed & 42 & 33 & 75 \\
Dead & 3 & 11 & 14 \\
In hospital & 1 & 1 & 2 \\
Abroad & 3 & 5 & 8 \\
Untraced & 3 & 0 & 3 \\
\hline Totals & 52 & 50 & 102 \\
\hline
\end{tabular}

these men had worked at some time in both preparing and non-preparing departments. These have been grouped according to the department in which the greater proportion of time had been spent. In all but five cases these men had spent $75 \%$ or more of their total time in the mill in one or other type of department.

The age distributions of preparers and nonpreparers at the time of interview do not differ significantly* $\left(\chi^{2}=3.97 ;\right.$ D.F. $=3 ; 0.30>\mathrm{P}>$ $0 \cdot 20)$ nor do the distributions of their ages at the time they left the mill $\left(\chi^{2}=4 \cdot 18 ;\right.$ D.F. $=3 ; 0.30>$ $P>0 \cdot 20$ ). The smoking habits of these two groups when seen were also very similar $\left(\chi^{2}=2 \cdot 28 ;\right.$ D.F. $=$ $2 ; 0.50>P>0.30$ ).

Respiratory Symptoms. - The number of workers who had symptoms of chronic bronchitis is shown in Table 2. There is no significant difference between

*The criterion of significance used throughout is $P<0.05$.

TABLE 2

DISTRIBUTION OF WORKERS BY CHRONIC BRONCHITIS GRADE* AND OCCUPATION

\begin{tabular}{l|c|c|c}
\hline \multicolumn{1}{c|}{$\begin{array}{c}\text { Chronic Bronchitis } \\
\text { Grade* }\end{array}$} & Preparers & Non-preparers & Totals \\
\hline Nil & 28 & 19 & 47 \\
Simple & 7 & 8 & 15 \\
With exacerbation & 7 & 6 & 13 \\
\hline Totals & 42 & 33 & 75 \\
\hline
\end{tabular}

*See text. $x^{2}=0.80 ;$ D.F. $=2 ; 0.70>$ P $>0.50$.

TABLE 3

DISTRIBUTION OF WORKERS BY DYSPNOEA GRADE* AND OCCUPATION

\begin{tabular}{|c|c|c|c|}
\hline Symptom Grade* & Preparers & Non-preparers & Totals \\
\hline $\begin{array}{l}\text { Heart trouble, etc. } \\
\text { (see text) }\end{array}$ & 4 & 5 & 9 \\
\hline $\begin{array}{c}\text { Dyspnoea grade I } \\
\text { grade II } \\
\text { grade III } \\
\text { grade IV }\end{array}$ & $\left.\begin{array}{r}25 \\
9 \\
3 \\
1\end{array}\right\} 13$ & $\left.\begin{array}{r}19 \\
7 \\
2 \\
-\end{array}\right\} 9$ & $\begin{array}{r}44 \\
16 \\
5 \\
1\end{array}$ \\
\hline Totals & 42 & 33 & 75 \\
\hline
\end{tabular}

*See text.

Workers with heart trouble, etc. were omitted, and brackets show grouping for $\chi^{2}$ test. $\chi^{2}=0.01 ;$ D.F. $=1 ; 0.95>$ P $>0.9$. the proportion of preparers and non-preparers with these symptoms at the time of interview, nor do these two groups differ significantly in the proportions who complained of exertional dyspnoea when seen (Table 3).

Significantly more men who had worked in preparing departments had had symptoms of byssinosis while in the mill than those who had worked in other departments (Table 4). Six non-preparers had had byssinosis, four of these had worked as 'bundlers' packing yarn for dispatch from the mill, the other two (both maintenance workers) had worked intermittently in preparing rooms. Altogether 10 of the men in this study had had jobs

TABLE 4

DISTRIBUTION OF WORKERS BY BYSSINOSIS GRADE* AND OCCUPATION

\begin{tabular}{|c|c|c|c|}
\hline Byssinosis Grade* & Preparers & Non-preparers & Totals \\
\hline 0 & 17 & 27 & 44 \\
\hline$\frac{1}{2}$ & $4]$ & - & 4 \\
\hline I and II & $21 \int^{20}$ & $6 \int^{0}$ & 27 \\
\hline Totals & 42 & 33 & 75 \\
\hline
\end{tabular}

*See text.

Brackets show grouping for $\chi^{2}$ test. $\chi^{2}=11 \cdot 38$; D.F. $=1$; P $<$ 0.001 .

which, although non-preparing, were either dusty (e.g., bundling) or necessitated work in a dusty room for considerable periods (e.g., maintenance workers). Six of these men had had byssinosis, and this proportion $(60 \%)$ is almost identical with that of the men who had worked in preparing departments alone ( 25 out of 42 , or $60 \%$ approximately).

Thirty-one men in all had had byssinosis. Sixteen of these gave evidence of having been disabled to some extent by exertional dyspnoea while at work in the mill. Most of the latter said that breathlessness had caused them some difficulty in getting home from the mill; this was said usually to have been particularly bad at the beginning of each week, though only a few had had to stop for breath while walking. Most said that they had then been less fit generally than their fellow workers from other departments.

At the time of interview, although the proportion of men who admitted to exertional dyspnoea did not differ significantly between the two occupational groups (Table 3), 14 men, all of whom had had byssinosis, thought that work in the mill had had a permanent effect on their chests. Table 5 shows that at the time of interview dyspnoea on exertion was admitted to by significantly more men who had had byssinosis than by men who had not. 
TABLE 5

DISTRIBUTION OF WORKERS BY DYSPNOEA GRADE* AND WHETHER OR NOT SYMPTOMS OF BYSSINOSIS* HAD BEEN PRESENT WHEN IN THE MILL

\begin{tabular}{|c|c|c|c|}
\hline \multirow{2}{*}{ Dyspnoea Grade* } & \multicolumn{2}{|c|}{$\begin{array}{l}\text { Symptoms of Byssinosis* } \\
\text { when in the Mill }\end{array}$} & \multirow{2}{*}{ Totals } \\
\hline & Present & Absent & \\
\hline Heart trouble, etc. (see text) & 5 & 4 & 9 \\
\hline Dyspnoea grade I & 13 & 31 & 44 \\
\hline grade II & & & 16 \\
\hline grade III + & $5\}^{13}$ & $1\}^{9}$ & 6 \\
\hline Totals excluding heart trouble & 26 & 40 & 66 \\
\hline
\end{tabular}

*See text.

Workers with heart trouble were excluded, and brackets show grouping for $x^{2}$ test: $x^{2}=4.20 ;$ D.F. $=1 ; 0.05>P>0.02$.

Reasons for having left the Mill.-Relatively more of the men who had worked in preparing departments (both those under the age of 65 years and those who were 65 years of age and over at the time of leaving) mentioned increasing exertional dyspnoea as a reason for having left than did those of comparable age who had worked in non-preparing departments, though the difference between all preparers and all non-preparers is not significant $\left(\chi^{2}=\right.$ $4.00 ;$ D.F. $=2 ; 0.20>P>0 \cdot 10$ ). However, if the 10 men who had been exposed to flax dust during their work but who were classed as non-preparers (see above) are grouped with those who had worked in preparing departments, a significantly greater proportion of these 'exposed' workers mentioned increasing exertional dyspnoea as a reason for having left than did those men who had not been exposed $\left(25 \%\right.$ and $4 \%$ respectively; $\chi^{2}=10 \cdot 14 ;$ D.F. $=2$;

TABLE 6

DISTRIBUTION OF WORKERS BY REASON FOR HAVING LEFT THE MILL, AGE ON LEAVING THE MILL, AND WHETHER OR NOT SYMPTOMS OF BYSSINOSIS HAD BEEN PRESENT WHILE WORKING IN THE MILL

\begin{tabular}{|c|c|c|c|c|c|}
\hline \multirow{4}{*}{$\begin{array}{l}\text { Reason for having } \\
\text { left the Mill }\end{array}$} & \multicolumn{4}{|c|}{ Age when left the Mill } & \multirow{4}{*}{ Totals } \\
\hline & \multirow{2}{*}{\multicolumn{2}{|c|}{$\begin{array}{c}\text { Under } 65 \text { years } \\
\text { Byssinosis } \dagger\end{array}$}} & \multirow{2}{*}{\multicolumn{2}{|c|}{$\begin{array}{c}65 \text { years or more } \\
\text { Byssinosis } \dagger \\
\end{array}$}} & \\
\hline & & & & & \\
\hline & Present & Absent & Present & Absent & \\
\hline \multirow{3}{*}{$\begin{array}{l}\text { Dyspnoea* } \\
\text { Dyspnoea* } \\
\text { other reason } \\
\text { Ilness other than } \\
\text { above }\end{array}$} & $7\} 9$ & $1\}_{1}$ & $\left.{ }^{2}\right\}_{3}$ & $-\zeta_{1}$ & 10 \\
\hline & $2 \int$ & - & $1 \int^{0}$ & $1 \int^{1}$ & 4 \\
\hline & 7 & 4 & 2 & 3 & 16 \\
\hline Other reason & 6 & 20 & 4 & 15 & 45 \\
\hline Totals & 22 & 25 & 9 & 19 & 75 \\
\hline
\end{tabular}

*See text.

$\dagger$ Refers to period of employment in the mill.

Two age groups amalgamated and brackets show grouping for $\chi^{2}$

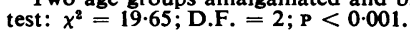

$0.01>P>0.001)$. The same trend is evident if those who had byssinosis are compared with those who had not had byssinosis; a significantly higher proportion of the former than of the latter mentioned dyspnoea as a reason for leaving $(39 \%$ and $5 \%$ respectively; Table 6).

Progress of Byssinosis. - Of the 31 men who had had byssinosis while working, two said that their symptoms had become worse since they had left the mill. One of these two who had had byssinosis grade II and who had left the mill at the age of 51 years because of exertional dyspnoea had continued during the four years since he had left the mill to have dyspnoea of increasing severity. The other, who had also had byssinosis grade II, had left the mill six years previously at age 60 years because of increasing exertional dyspnoea. The chief complaint of this man was a cough which had started during work in the mill and which had gradually become worse even after he had left the mill, and when seen this was said to be particularly severe on cold or wet nights. Both of these men had symptoms of chronic bronchitis with a recent exacerbation.

Two others had noticed only a little improvement in their symptoms after leaving the mill but all the remainder had noticed an improvement which was said by most to have been marked and which had usually commenced within a week or two of leaving the mill. This had frequently continued for several years and was said by two men, who had left six and nine years previously, to be still continuing. Fourteen of the men who had had byssinosis thought that work in the mill had had a permanent deleterious effect on their chests. However, the other 17 men who had had byssinosis said they felt as fit as other men of their age, and five had taken up light work since leaving the mill.

Copies of the certificates of the cause of death could only be obtained for 12 of the 14 men who had died. "Two men had died outside Northern Ireland at an unknown time and place. The total length of time each had worked in the industry is unknown, but all were thought by the management to have spent most of their working life in the mill. A much higher proportion of men who had worked in non-preparing departments $(22 \%)$ had died than had men who had worked in preparing departments $(6 \%)$, though, of these former, three had at one time worked in a preparing department. Respiratory disease had been entered on the death certificate of only one man, a flax preparer aged 66 years at death, who was certified to have died from cerebral thrombosis, though chronic bronchitis had been considered to have been a 'significant condition, 
contributing to the death'. The other preparers had died from non-respiratory causes, three from cardiovascular disease, one from carcinoma of the prostate, and one from cirrhosis of the liver. Six who are not known to have worked in preparing rooms, and all of whom were over 60 years of age at death, had all died from non-respiratory causes, three from cardiovascular disease, two from carcinoma, and one from cerebral thrombosis.

\section{Discussion}

This study suggests that while respiratory symptoms attributable to work in preparing and other dusty rooms in a flax mill may improve after discharge from the mill, there may be, at any rate in older workers who have had byssinosis, some residual symptoms which may be permanent. The prevalence of exertional dyspnoea was found to be twice as high in men who had had byssinosis than in those who had not had it while in the mill, and this difference is significant. Furthermore, it appears that disability due to increasing exertional dyspnoea may be a more frequent cause of discharge from the mill in older men who have been exposed to flax dust and in those who have had byssinosis than in other men.

This study gives no evidence that byssinosis is an important cause or a contributory cause of death, though the number of deaths available for study is very small. However, it is of interest that although some of the men in this study who had had byssinosis claimed at interview that they were then as fit as other men of their age, nearly half said that they felt that work in the mill had permanently affected their chests. Of particular interest in this context are two men who had had severe byssinosis and who at interview stated that their symptoms had become worse since discharge. The fact that some chest symptoms persisted in nearly half of the affected workers after leaving the mill, and progressed in some of these, supports the view of Elwood, Pemberton, Merrett, Carey, and McAulay (1965) that byssinosis may include a basic chronic bronchitic process.

The mill on which the present data are based cannot be taken as typical of all or even most flax mills in Northern Ireland since it was in a rural district a considerable distance from any source of air pollution and from any large-scale source of alternative employment. Most of the flax mills in the province are situated in or close to industrial areas. Therefore it is impossible to make a quantitative estimate of the problems studied here in the industry as a whole, or of their effects on the epidemiological picture of byssinosis and other respiratory symptoms. However, the study does suggest that the problem of byssinosis in the flax-spinning industry will be underestimated if it is assessed solely on the prevalence of the condition in workers at present working in the mills.

I wish to thank the management and welfare officer of the mill on which this study was based for considerable help, and Professor J. Pemberton for advice and encouragement.

\section{REFERENCES}

Cochrane, A. L., and Higgins, I. T. T. (1961). Brit. J. prev. soc. Med., $15,1$.

Elwood, P. C., Pemberton, J., Merrett, J. D., Carey, G. C. R., and McAulay, I. R. (1965). Brit. J. industr. Med., 22. 27.

General Register Office (1958). Decennial Supplement, England and

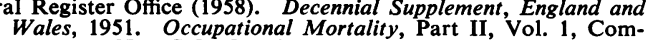
mentary. H.M.S.O., London.

Heasman, M. A., Liddell, F. D. K., and Reid, D. D. (1958). Brit. J. industr. Med., 15, 141.

Medical Research Council (1960). Instructions for the Use of the Questionnaire on Respiratory Symptoms.

Purdon, C. D. (1873). The Mortality of Flax Mill and Factory Workers as compared with Other Classes of the Community. Adair,

(1875). Longevity of Flax Mill and Factory Operatives. Adair,

Belfast.
(1877). The Sanitary State of the Belfast Factory District during the Ten Years (1864 to 1873) under Various Aspects. Adair, Belfast.

Roach, S. A., and Schilling, R. S. F. (1960). Brit. J. industr. Med. 17, 1 . 